\title{
DVB Regimen
}

National Cancer Institute

\section{Source}

National Cancer Institute. DVB Regimen. NCI Thesaurus. Code C9571.

A chemotherapy regimen consisting of cisplatin, bleomycin and vindesine that may be used in the treatment of non-small cell lung cancer. 